\title{
STABILISASI TANAH LEMPUNG DENGAN CAMPURAN FLY ASH (FA) DAN EXPANDED POLYSTYRENE (EPS) SEBAGAI ALTERNATIF TIMBUNAN RINGAN PADA LAPISAN SUBGRADE
}

\author{
Hendry $^{1}$, Reni Rahmawati ${ }^{2}$, Syifa Andriani ${ }^{2}$ \\ ${ }^{1}$ Dosen Jurusan Teknik Sipil Politeknik Negeri Bandung \\ E-mail: hendry@polban.ac.id \\ ${ }^{2}$ Lulusan D3 Teknik Konstruksi Sipil, Jurusan Teknik Sipil Politeknik Negeri Bandung
}

\begin{abstract}
ABSTRAK
Tanah lunak tidak digunakan sebagai timbunan dalam proyek konstruksi, karena memiliki nilai CBR yang rendah tetapi dengan nilai kepadatan kering yang tinggi, ini sangat rentan kegagalan daya dukung pada lapisan tanah dasar konstruksi jalan. Tanah lempung lunak dapat digantikan dengan material lain sebagai timbunan, tetapi akan menambah biaya. Dalam penggunaan tanah lunak sebagai tanah dasar untuk perkerasan jalan, maka penambahan expanded polystyrene (EPS) dan fly ash (FA) perlu dicoba untuk diteliti. Penelitian dilakukan untuk melihat nilai uji CBR di laboratorium pada campuran tanah lempung, fly ash (FA) dan expanded polystyrene (EPS). Komposisi campuran dilakukan dengan penambahan EPS sebanyak $0 \%$; 0,25\%; 0,5\%; dan 0,75\% dengan waktu peram selama 3, 7, 14, 21 hari. Pada penelitian ini komposisi untuk FA ditetapkan sebanyak 16\%, diambil berdasarkan beberapa penelitian sebelumnya. Pada komposisi dengan penambahan EPS sebesar 0,75 \% dengan waktu peram 14 hari, merupakan komposisi yang optimal karena menghasilkan nilai CBR tinggi dan $\gamma_{\mathrm{d}}$ rendah jika dibandingkan dengan tanah lunak, dengan nilai CBR pada kondisi unsoaked 2,84\% dan d 1,0 gr/ $\mathrm{cm}^{3}$ dan kondisi soaked 2,27\% dan d 1,1 gr/ $/ \mathrm{cm}^{3}$. Penelitian ini bertujuan seperti penelitian serupa untuk penambahan semen sebagai aktivasi fly ash sehingga memiliki performansi yang lebih baik dari sebelumnya, sehingga dapat memaksimalkan hasil nilai CBR campuran tanah.
\end{abstract}

Kata kunci : tanah lunak, fly ash, expanded polystyrene, CBR

\section{ABSTRACT}

Clay soil as embankment has a low CBR value with high dry density value, so this is very susceptible to failure of the bearing capacity of the subgrade of road construction. Clay soil can be replaced by selected material as embankment, but this will be increase costs. For clay soil to be used as a subgrade for road construction, the addition of fly ash (FA) and expanded polystyrene (EPS) needs to try by this research. The research was done by testing CBR in laboratory on the soil mixture, fly ash (FA), and expanded polystyrene (EPS). The composition was done by addition of EPS as a mixture as $0 \% ; 0.25 \%$; $0.50 \%$; and $0.75 \%$ with curing time of 3, 7, 14, 21 days. In this study, composition for FA set as much as 16\%, based on some previous research. In the compositions with addition of EPS as much as $0.75 \%$ with curing time 14 day, is the optimal composition because high CBR value and low $\gamma_{d}$ if compared to original clay soil. CBR value on the unsoaked condition were $2.84 \%$ and $\gamma d 1.03 \mathrm{gr} / \mathrm{cm}^{3}$, while in the soaked condition were $2.27 \%$ and $\gamma_{d} 1.06 \mathrm{gr} / \mathrm{cm}^{3}$. The addition of other materials such as cement needs to be a further researched as fly ash activation, so that fly ash has more performance, so that it can maximize the CBR value of the mixture.

Keywords: clay, fly-ash, expanded polystyrene, CBR

\section{PENDAHULUAN \\ 1.1 Latar Belakang}

Indonesia, sebagai negara berkembang saat ini sedang giatnya melaksanakan pembangunan infrastruktur jalan dan jembatan yang merata di semua daerah agar dapat meningkatkan perekonomian nasional. Pada pekerjaan pembangunan jalan salah satunya adalah pekerjaan lapisan tanah dasar (subgrade), yang merupakan lapisan paling bawah (tanah) yang berfungsi untuk menumpu lapisan perkerasan dan berpengaruh terhadap konstruksi perkerasan jalan di atasnya sehingga subgrade sangat berpengaruh terhadap baik buruknya perkerasan jalan. Di beberapa proyek pembangunan jalan, tanah yang ada di lokasi tersebut bukan merupakan tanah yang cocok dijadikan sebagai subgrade untuk perkerasan jalan, karena jenis tanahnya merupakan tanah lunak (lempung) sehingga cenderung dibuang atau tidak dimanfaatkan. Tanah jika tidak dikenali dan diselidiki secara berhati-hati dapat menyebabkan masalah ketidakstabilan dan penurunan jangka panjang yang tidak dapat ditolerir. Tanah lunak mempunyai kuat geser yang rendah dengan nilai kompresibilitas (kemampumampatan) yang tinggi. Dengan permasalahan ketidakstabilan dan penurunan, maka tanah lunak perlu diperbaiki agar dapat diaplikasikan pada pekerjaan infrastruktur jalan. Perbaikan tanah dapat dilakukan dengan berbagai cara, salah satu caranya dengan penambahan fly ash untuk meningkatkan kekuatan tanah. Penambahan fly ash akan berpengaruh terhadap nilai indeks plastisitas yang secara tidak langsung akan berpengaruh juga terhadap nilai CBR yang semakin meningkat. 
Perbaikan tanah lempung dengan penambahan fly ash dapat diaplikasikan jika berat isi tanah hasil penambahan fly ash lebih ringan dari tanah aslinya. Untuk mengurangi berat isinya sehingga menjadi timbunan ringan, maka salah satu alternatif materialnya yaitu penambahan expanded polystrene (EPS). Penggunaan EPS pada subgrade dapat mengurangi berat isi tanah, sehingga total berat subgrade dan beban perkerasan lainnya menjadikan pembebanan pada tanah di bawahnya dapat berkurang. Dari uraian ini maka penambahkan FA dan EPS sebagai alternatif campuran diharapkan subgrade akan memiliki berat isi yang lebih ringan tetapi dengan nilai CBR yang tetap tinggi.

\subsection{Rumusan Masalah}

Penggunaan tanah lempung sebagai timbunan pada proyek pembangunan jalan, sering menimbulkan kegagalan terhadap daya dukung karena memiliki nilai CBR yang kecil tetapi dengan berat isi kering relatif besar, sehingga merusak konstruksi perkerasan, dan jika diganti dengan tanah lain akan timbul masalah pembengkakan biaya konstruksi.

\subsection{Tujuan Penelitian}

Mendapatkan komposisi pencampuran fly ash dengan persentase yang tetap dan komposisi expanded polystyrene pada tanah lempung yang dapat menghasilkan nilai CBR yang tinggi dan berat isi yang rendah, sebagai alternatif timbunan ringan pada lapisan subgrade.

\subsection{Hipotesis}

Pencampuran tanah lempung dengan fly ash dan expanded polystyrene dalam proses pemadatan tanah sebagai bahan timbunan, maka tanah akan memiliki nilai berat isi yang kecil dan nilai CBR yang meningkat, sehingga akan mengurangi tebal lapisan perkerasan di atas lapisan tanah dasar (subgrade). Dengan penggunaan campuran ini akan menjadikan berat sendiri lapisan tanah dasar konstruksi perkerasan jalan berkurang, dan hal ini akan dapat menghindari terjadinya kegagalan daya dukung pada tanah dasar yang lunak.

\subsection{Lokasi Penelitian}

Material tanah dan bahan yang digunakan dalam penelitian ini adalah Tanah Lempung sendiri, Fly ash dan EPS, yang diambil atau berasal dari :

1. Tanah Lempung dari daerah Gedebage Kota Bandung.

\section{Fly ash dari PLTU Suralaya, Cilegon, Banten.}

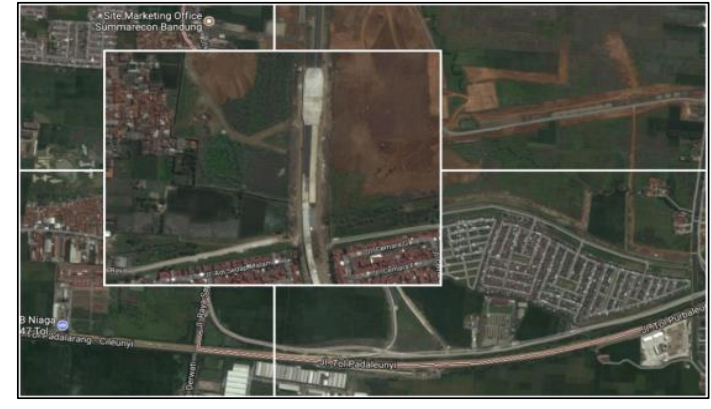

Gambar 1. Lokasi Pengambilan Tanah

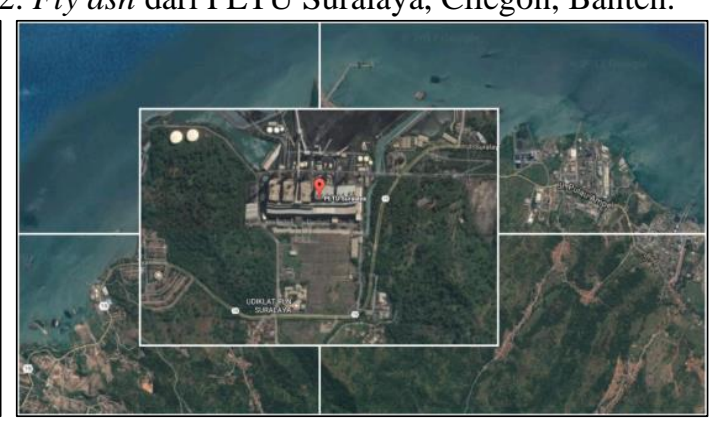

Gambar 2. Lokasi Pengambilan Fly Ash

3. EPS berasal dari B-foam EPS, PT Beton Elemenindo Putra, Batujajar, Kabupaten Bandung Barat.

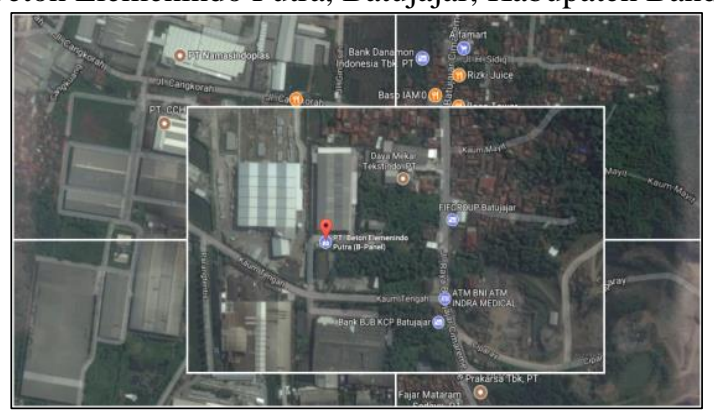

Gambar 3. Lokasi Pengambilan EPS

\section{LANDASAN TEORI}

\subsection{Tanah Lempung}

Berdasarkan ukuran partikelnya seperti yang di definisikan oleh Bowles (1884), tanah lempung adalah deposit yang mempunyai partikel berukuran lebih kecil atau sama dengan 0,002 mm. Sedangkan kandungan mineral yang ada di dalam tanah lempung mempunyai daya tarik menarik individual yang mampu menyerap 100 kali volume partikelnya. Dan selama proses pengeringan, apakah ada atau tidak adanya air dapat menghasilkan perubahan volume dan kekuatan yang sangat besar. 


\subsection{Fly Ash}

Fly ash adalah berasal dari atau merupakan bahan limbah atau buangan dari pembakaran batu bara yang dikategorikan sebagai limbah B3 (PP No. 85 tahun 1999 tentang Pengelolaan Limbah Bahan Berbahaya dan Beracun. Fly ash menjadi suatu bahan tambah (additive) yang cukup populer saat ini pada pekerjaan konstruksi untuk digunakan sebagai pengganti sebagian semen dalam campuran beton dan banyak juga digunakan sebagai bahan untuk stabilisasi tanah. Fly ash dikalsifikasikan dalam 3 kelas, yaitu kelas F, kelas C dan kelas N. Fly ash kelas F (low-calcium fly ash), tidak mempunyai sifat cementitious dan hanya bersifat pozolanic. Fly ash kelas $\mathrm{C}$ disebut juga sebagai high-calcium fly ash karena fly ash tipe $\mathrm{C}$ mengandung kadar CaO yang cukup tinggi dan mempunyai sifat cementitious dan posolan. Fly ash kelas $\mathrm{N}$ disebut juga posolan alam yang mempunyai sifat posolan yang baik.

Pengaruh Fly Ash terhadap Nilai CBR dan sifat-sifat properties Tanah, sudah diteliti oleh Inten Subowo (2016). Berdasarkan hasil penelitiannya dimana dengan mencampurkan fly ash dan tanah ekspansif dengan kadar fly ash yang digunakan mulai $0 \%$, $10 \%, 20 \%$, 30\% dan 40\% dan tanpa pemeraman (masa peram 0 hari), didapatkan nilai CBR maksimum (37,2\%) pada penambahan fly ash sebesar 20\%. Sedangkan penelitian yang dilakukan Yayuk Apriyanti dan Roby Hambali (2014) tentang pemanfaatan fly ash sebagai bahan stabilisasi tanah lempung jenis A-7-6 dengan variasi kadar fly ash mulai 10\%, 13\%, 16\% dan masa peram 1, 7, 14, dan 28 hari, menghasilkan peningkatan nilai CBR. Nilai CBR maksimum $(15,1 \%)$ didapat pada persentase kadar fly ash 16\% dengan masa peram 28 hari.

\subsection{Expanded Polystyrene}

Expanded Polystyrene (EPS) yang dikenal umum sebagai styrofoam, merupakan material yang terbuat dari monomer stirena melalui proses polimerisasi suspensi pada tekanan dan suhu udara tertentu, kemudian dilakukan pemanasan untuk melunakkan resin dan menguapkan sisa blowing agent. EPS terlihat berwarna putih dengan berat yang relatif sangat ringan, ini termasuk ke dalam kategori plastik. Secara umum EPS banyak digunakan untuk pembungkus makanan dan pengemasan barang elektronik. Saat ini EPS juga dimanfaatkan sebagai material konstruksi, di mana salah satunya, sebagai material timbunan ringan pada sebagian besar pekerjaan tanah (Horvath, 1995).

Penelitian yang dilakukan oleh Hema Kumar Illuri (2007) dengan cara memodifikasi campuran tanah lempung ekspansif dengan penambahan EPS dan sand bentonite (SB) memperlihatkan hasil penurunan pada berat isi kering maksimumnya. Pada penambahan 0,9\% EPS, berat kering tanah campuran SB16 turun dari $17,06 \mathrm{kN} / \mathrm{m}^{3} \mathrm{ke} 13,24 \mathrm{kN} / \mathrm{m}^{3}$. Pada penggunaan SB24, nilai berat isi keringnya turun dari $17.27 \mathrm{kN} / \mathrm{m}^{3} \mathrm{ke} 12,56 \mathrm{kN} / \mathrm{m}^{3}$, sedangkan untuk SB32 dari $16,97 \mathrm{kN} / \mathrm{m}^{3} \mathrm{ke} 12.26 \mathrm{kN} / \mathrm{m}^{3}$. Di sisi lain saat hasil daur ulang EPS dengan kadar 0\%, 0,3\%, 0,6\% dan 0,9\% memperlihatkan semakin tinggi kadar EPS pada campuran maka dapat mengurangi kekuatan geser campuran. Penambahan dengan stabilizer kimia baru dapat meningkatkan kekuatan dan sifat campuran secara keseluruhan.

Menurut Nicholas Thomas Rocco (2012), pada penelitiannya dengan bijih EPS ditambahkan dengan kadar sampai $1,5 \%$ dari berat tanah lempung memberikan efek yang besar pada berat volume campuran, di mana setiap peningkatan $0,5 \%$ kadar EPS dapat mengurangi berat isi kering sebesar 8\%-12\%. Efek lain adalah pada penambahan kadar EPS yang lebih dari $1 \%$ akan mengakibatkan penurunan pada kekuatan geser bila dibandingkan dengan tanah aslinya.

\subsection{Stabilisasi Tanah}

Bila mutu suatu tanah kurang baik, maka dapat ditingkatkan dengan suatu proses yang disebut dengan stabilisasi. Jadi Stabilisasi tanah bertujuan untuk memperbaiki mutu kekuatan tanah dasar yang kurang baik agar menjadi lebih baik. Dengan stabilisasi ini dimaksudkan untuk menstabilkan konstruksi yang dibangun di atas tanah dasar yang kurang baik, dengan meningkatnya daya dukung tanah yang distabilkan tadi. Stabilisasi tanah dasar untuk perbaikan mutunya dapat dilakukan dengan beberapa cara/metode di antaranya, dengan Stabilisasi Mekanik, Stabilisasi Fisik, Stabilisasi Kimiawi

\subsection{Pengujian di Laboratorium}

Untuk dapat mengetahui karakteristik dan sifat tanah, maka dilakukan pengujian di laboratorium yang mengacu ke standar yang berlaku yaitu Standar Nasional Indonesia (SNI) seperti terlihat pada Tabel 1. 
Tabel 1. Jenis Pengujian Tanah

\begin{tabular}{|c|c|c|c|}
\hline No & \multicolumn{2}{|c|}{ Jenis Pengujian } & Standar yang digunakan \\
\hline A. & \multicolumn{3}{|c|}{ SIFAT FISIK } \\
\hline 1. & \multicolumn{2}{|l|}{ Kadar Air } & SNI 03-1965-1990 \\
\hline 2. & \multicolumn{2}{|l|}{ Berat Jenis } & SNI 03-1964-2008 \\
\hline \multirow{2}{*}{3.} & \multirow{2}{*}{$\begin{array}{l}\text { Batas-Batas } \\
\text { Atterberg }\end{array}$} & Batas Cair & SNI 03-1967-2008 \\
\hline & & Batas Plastis & SNI 03-1966-2008 \\
\hline 4. & \multicolumn{2}{|c|}{ Analisa Ukuran Butir } & SNI 03-3423-2008 \\
\hline B. & \multicolumn{3}{|c|}{ SIFAT MEKANIS } \\
\hline 1. & \multicolumn{2}{|l|}{ Pemadatan } & SNI 03-1742-2008 \\
\hline 2. & \multicolumn{2}{|c|}{ CBR Laboratorium } & SNI 03-1744-2012 \\
\hline
\end{tabular}

\section{METODE PENELITIAN}

Secara keseluruhan pengujian di lakukan di laboratorium dengan mengikuti standar pengujian yang berlaku, dimulai dengan pengujian sifat fisik tanah, dilanjutkan pengujian sifat mekanik untuk tanah saja dan terakhir dengan pengujian sifat fisik campuran. Pada uji mekanik campuran difokuskan pada uji CBR dengan penambahan fly ash sebanyak $16 \%$ dan expanded polystyrene (EPS) empat variasi yaitu $0 \%, 0,25 \%, 0,50 \%$, dan $0,75 \%$ dari berat total campuran, dan dilakukan pemeraman (didiamkan) setalah pemadatan selama 3, 7, 14, dan 21 hari. Komposisi campuran yang dapat dilihat pada Tabel 2.

Tabel 2. Komposisi Campuran

\begin{tabular}{|c|c|c|c|}
\hline Lempung & Fly Ash & EPS & Masa Peram \\
\hline$(\%)$ & $(\%)$ & $(\%)$ & (hari) \\
\hline 84.00 & 16 & 0.00 & $3,4,14,21$ \\
\hline 85.75 & 16 & 0.25 & $3,4,14,21$ \\
\hline 83.75 & 16 & 0.50 & $3,4,14,21$ \\
\hline 83.25 & 16 & 0.75 & $3,4,14,21$ \\
\hline
\end{tabular}

\section{HASIL DAN PEMBAHASAN}

4.1 Pengujian Sifat Fisik

Hasil pengujian sifat fisik dapat dilihat pada Tabel 3.

Tabel 3. Hasil pengujian Sifat Fisik Tanah

\begin{tabular}{|c|c|c|c|c|c|}
\hline No & \multicolumn{2}{|c|}{ Sifat Fisik } & Simbol & Satuan & Hasil Pengujian \\
\hline 1 & Berat Jenis & & Gs & & 2,36 \\
\hline \multirow[t]{3}{*}{2} & \multirow{3}{*}{$\begin{array}{l}\text { Batas-batas } \\
\text { Atterberg }\end{array}$} & Batas Plastis & PL & $\%$ & 38,26 \\
\hline & & Batas Cair & $\mathrm{LL}$ & $\%$ & 62,42 \\
\hline & & Indeks Plastisitas & PI & $\%$ & 24,16 \\
\hline \multirow[t]{4}{*}{3} & \multirow{4}{*}{$\begin{array}{l}\text { Analisa } \\
\text { Ukuran } \\
\text { Butir }\end{array}$} & Kerikil & $\mathrm{G}$ & $\%$ & 0,00 \\
\hline & & Pasir & $\mathrm{S}$ & $\%$ & 4,99 \\
\hline & & Lanau & M & $\%$ & 38,60 \\
\hline & & Lempung & $\mathrm{C}$ & $\%$ & 56,41 \\
\hline
\end{tabular}

\subsection{Klasifikasi Tanah}

\section{Klasifikasi secara AASHTO}

Secara ASSHTO tanah diklasifikasikan secara sebagai tanah A-7-5, karena persentase yang lolos saringan No 200 sebesar $95 \%$, dengan nilai batas cair (LL) sebesar 62,42\% dan Indeks plastisitas (PI) sebesar $24,16 \%$,

\section{Klasifikasi secara USCS}

Untuk tanah yang sama dengan persentase lolos saringan No. 200 sebesar 95,01\%, nilai batas cair 62,42 \%, dan indeks plastisitasnya sebesar 24,16\%, diklasifikasikan secara USCS sebagai tanah MH.

\subsection{Hasil Pengujian Sifat Mekanis}

\section{Pemadatan Tanah (Kompaksi)}

Hasil pengujian pemadatan tanah lempung dengan 5 benda uji dengan penambahan air yang berbeda, setelah dibuatkan grafiknya (gambar 4) didapatkan nilai nilai $\omega_{\mathrm{opt}}=31,36 \%$ dan $\gamma_{\mathrm{d} \max }=1,295 \mathrm{gr} / \mathrm{cm}^{3}$. 


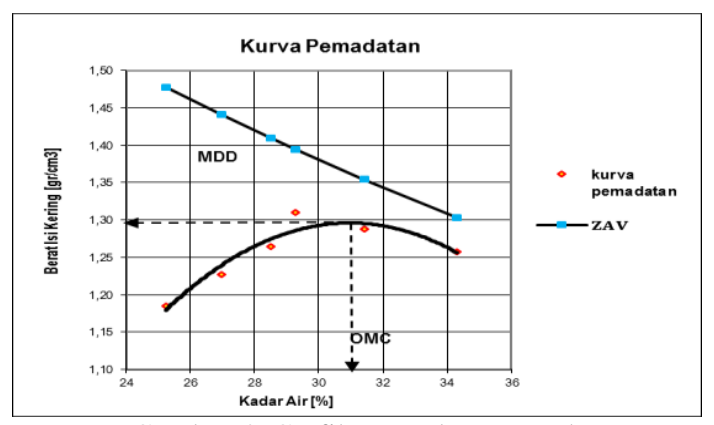

Gambar 4. Grafik Pemadatan Tanah

\section{California Bearing Ratio (CBR)}

Pengujian CBR dilakukan dengan energi pemadatan yang berbeda yaitu 10x, 30x, dan 65x. Pengujian dilakukan pada kondisi kering (unsoaked) dan basah (soaked), dengan hasil seperti dapat dilihat pada Gambar 5 dan Gambar 6.

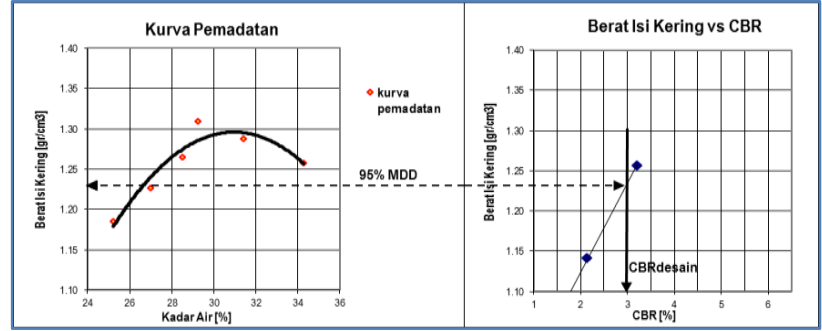

Gambar 5. Grafik CBR kondisi Unsoaked Tanah

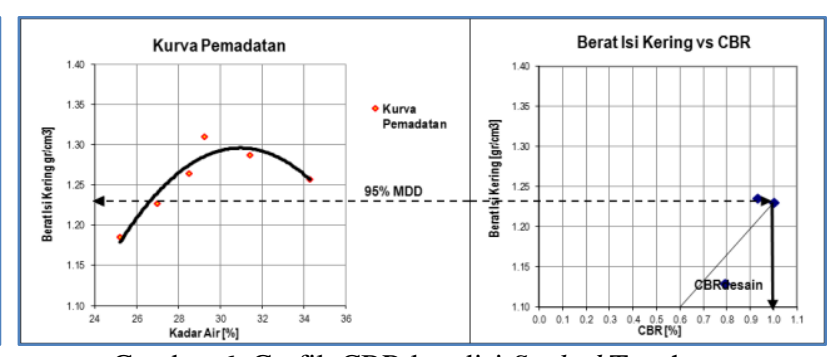

Gambar 6. Grafik CBR kondisi Soaked Tanah

Nilai CBR rencana diambil pada nilai berat isi kering $95 \%$ dari berat isi kering maksimum yaitu sebesar $1,23 \mathrm{gr} / \mathrm{cm}^{3}, \mathrm{setelah}$ ditarik garis penghubung di grafik didapatkan nilai CBR desain pada keadaan unsoaked (langsung diuji setelah pemadatan) sebesar 2,95\%, sedangkan nilai CBR desain kondisi soaked (setelah direndam selama 4x24 jam) didapat 1,00\%. Dari sini terlihat nilai CBR rencananya langsung turun akibat perendaman (kondisi kritis).

\subsection{Hasil Pengujian CBR Campuran Berdasarkan Komposisi}

Komposisi campuran (Tanah + FA + EPS) untuk pengujian CBR dilakukan dengan 4 variasi untuk mendapatkan komposisi campuran yang optimum. Pengujian CBR dilakukan pada dua kondisi, kondisi unsoaked dan kondisi soaked, dengan tiga energi yang berbeda sesuai standar, yaitu 10x, 30x, dan 65x tumbukan. Selain variasi campuran juga dilakukan pada beberapa kondisi perawatan / pemeraman. Proses ini dilakukan untuk memberikan kesempatan kepada campuran untuk bereaksi satu sama lainnya, sebelum di uji CBR-nya. Masa pemeraman yang dilakukan adalah selama : 3 hari, 7 hari, 14 hari dan 21 hari.

\section{Masa peram 3 hari}

Hasil Uji CBR untuk masa pemeraman selama 3 hari dapat dilihat pada tabel 4.

Tabel 4. Hasil Pengujian CBR Masa Peram 3 hari pada Kondisi Unsoaked dan Soaked

\begin{tabular}{|c|c|c|c|c|c|c|c|c|c|c|c|c|}
\hline \multicolumn{13}{|c|}{ Masa Peram 3 hari } \\
\hline & \multicolumn{6}{|c|}{ Unsoaked } & \multicolumn{6}{|c|}{ Soaked } \\
\hline & \multicolumn{3}{|c|}{$\gamma \mathbf{d}$} & \multicolumn{3}{|c|}{ CBR } & \multicolumn{3}{|c|}{$\gamma d$} & \multicolumn{3}{|c|}{ CBR } \\
\hline Komposisi & $10 x$ & $30 x$ & $65 x$ & $10 x$ & $30 x$ & $65 x$ & $10 x$ & $30 x$ & $65 x$ & $10 x$ & $30 x$ & $65 x$ \\
\hline I & 1.07 & 1.28 & 1.38 & 2.27 & 3.20 & 4.27 & 1.10 & 1.28 & 1.38 & 0.53 & 1.93 & 2.87 \\
\hline II & 1.05 & 1.20 & 1.26 & 1.87 & 2.49 & 3.3 & 1.08 & 1.20 & 1.26 & 0.58 & 1.51 & 2.00 \\
\hline III & 0.93 & 1.05 & 1.13 & 1.07 & 1.87 & 2.00 & 0.98 & 1.06 & 1.14 & 0.53 & 0.98 & 1.33 \\
\hline IV & 0.91 & 1.01 & 1.06 & 1.02 & 1.33 & 1.51 & 0.94 & 1.00 & 1.05 & 0.22 & 0.67 & 0.93 \\
\hline
\end{tabular}

Selanjutnya berdasarkan data dari Tabel 4 dapat dibuat grafik hubungan antara CBR dan $\gamma_{\mathrm{d}}$ dengan komposisi campuran pada energi 10x, 30x, dan 65x dalam keadaan unsoaked maupun soaked berturut-turut terlihat pada Gambar 7 dan gambar 8 . 


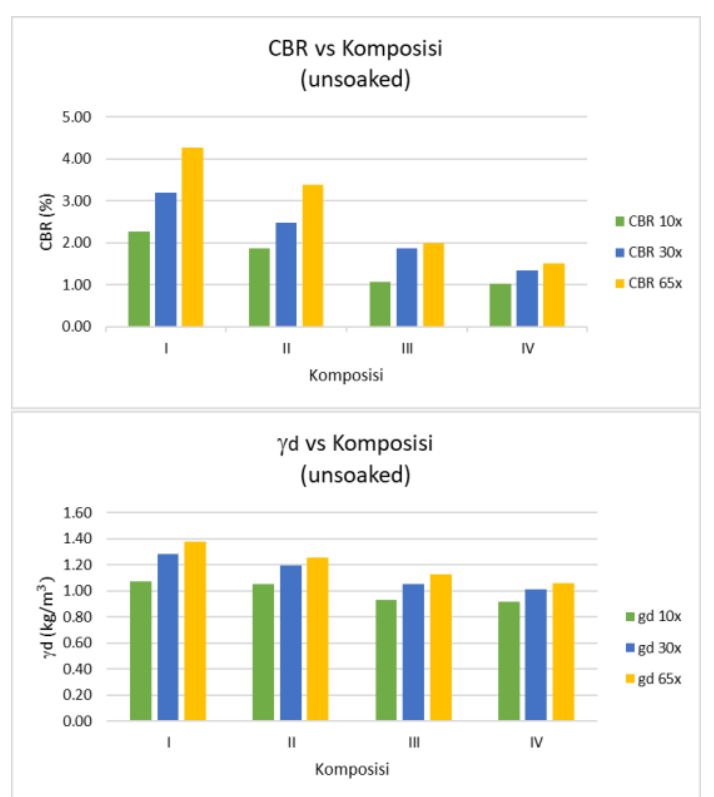

Gambar 7. Grafik CBR dan $\gamma_{\mathrm{d}}$ vs Komposisi (Unsoaked)

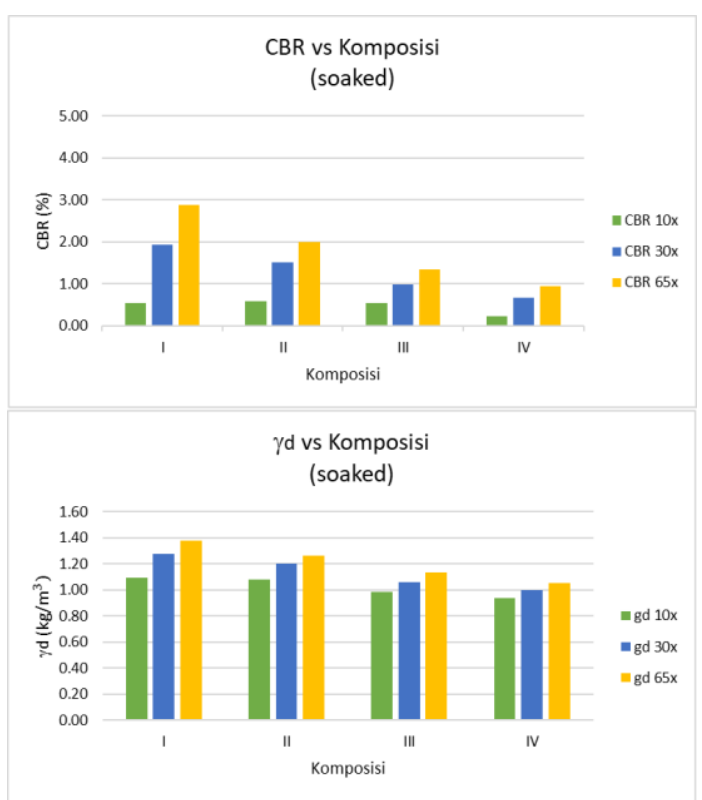

Gambar 8. Grafik CBR dan $\gamma_{\mathrm{d}}$ vs Komposisi (Soaked)

Nilai CBR tertinggi di dapat pada campuran komposisi I baik kondisi unsoaked maupun kondisi soaked (Gambar 8).

\section{Masa Peram 7 hari}

Hasil uji CBR dan nilai berat isi kering dengan masa peram 7 hari untuk setiap komposisi campuran adalah seperti data pada Tabel 5.

\begin{tabular}{|c|c|c|c|c|c|c|c|c|c|c|c|c|}
\hline \multicolumn{13}{|c|}{ Masa Peram 7 hari } \\
\hline \multirow[b]{3}{*}{ Komposisi } & \multicolumn{6}{|c|}{ Unsoaked } & \multicolumn{6}{|c|}{ Soaked } \\
\hline & \multicolumn{3}{|c|}{$\gamma d$} & \multicolumn{3}{|c|}{ CBR } & \multicolumn{3}{|c|}{$\gamma d$} & \multicolumn{3}{|c|}{ CBR } \\
\hline & $10 x$ & 30x & $65 x$ & $10 x$ & 30x & $65 x$ & $10 x$ & 30x & $65 x$ & $10 x$ & 30x & $65 x$ \\
\hline $\mathbf{I}$ & 1.09 & 1.25 & 1.34 & 0.89 & 3.91 & 4.80 & 1.12 & 1.28 & 1.35 & 0.49 & 1.60 & 2.13 \\
\hline II & 1.07 & 1.18 & 1.26 & 2.40 & 3.47 & 3.93 & 1.06 & 1.17 & 1.23 & 1.16 & 2.22 & 3.07 \\
\hline III & 1.02 & 1.29 & 1.57 & 2.93 & 2.84 & 3.38 & 1.03 & 1.06 & 1.60 & 0.44 & 1.33 & 2.20 \\
\hline IV & 0.91 & 1.02 & 1.05 & 1.87 & 1.87 & 2.00 & 0.94 & 1.05 & 1.06 & 0.53 & 0.60 & 1.00 \\
\hline
\end{tabular}

Selanjutnya berdasarkan data dari tabel 5, dapat dibuat grafik hubungan antara CBR dan $\gamma_{\mathrm{d}}$ dengan komposisi campuran pada energi 10x, 30x, dan 65x dalam keadaan unsoaked maupun soaked dapat dilihat pada Gambar 9 dan Gambar 10. 


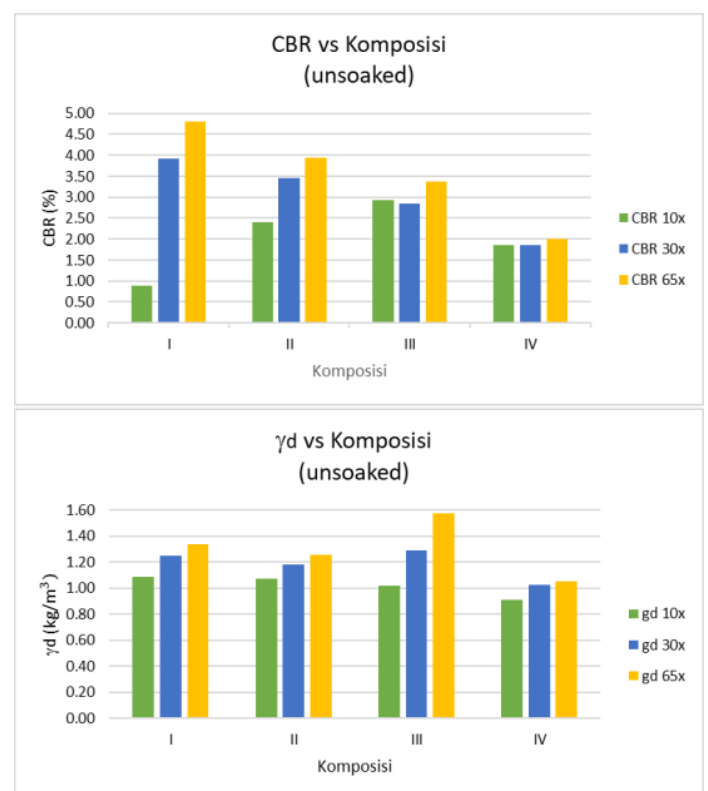

Gambar 9. Grafik CBR dan $\gamma_{\mathrm{d}}$ vs Komposisi (Unsoaked)

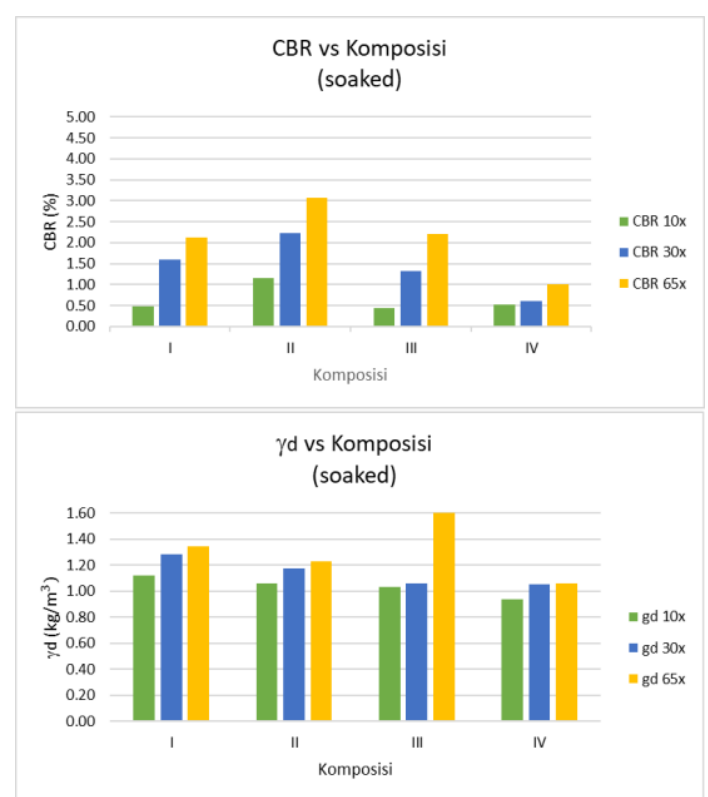

Gambar 10. Grafik CBR dan $\gamma_{\mathrm{d}}$ vs Komposisi (Soaked)

Pada kondisi soaked nilai CBR semua campuran turun dibandingkan dengan nilai CBR kondisi unsoaked. Nilai CBR tertinggi di dapat pada campuran komposisi I (Gambar 9) di kondisi unsoaked, tetapi pada kondisi soaked, nilai CBR tertinggi didapat pada campuran komposisi II (Gambar 10).

\section{Masa peram 14 hari}

Hasil uji CBR dan nilai berat isi kering dengan masa peram 14 hari adalah seperti terlihat pada Tabel 6.

Tabel 6. Hasil Pengujian CBR dengan Lama Masa peram 14 hari pada Keadaan Unsoaked dan Soaked

\begin{tabular}{|c|c|c|c|c|c|c|c|c|c|c|c|c|}
\hline \multicolumn{13}{|c|}{ Masa Peram 14 hari } \\
\hline & \multicolumn{6}{|c|}{ Unsoaked } & \multicolumn{6}{|c|}{ Soaked } \\
\hline & \multicolumn{3}{|c|}{$\gamma d$} & \multicolumn{3}{|c|}{ CBR } & \multicolumn{3}{|c|}{$\gamma \mathbf{d}$} & \multicolumn{3}{|c|}{ CBR } \\
\hline Komposisi & $10 x$ & $30 x$ & $65 x$ & $10 x$ & 30x & $65 x$ & $10 x$ & $30 x$ & $65 x$ & 10x & $30 x$ & $65 x$ \\
\hline I & 1.08 & 1.24 & 1.32 & 1.60 & 3.33 & 4.67 & 1.10 & 1.25 & 1.31 & 1.27 & 2.07 & 2.80 \\
\hline II & 1.05 & 1.16 & 1.21 & 1.73 & 1.87 & 3.51 & 1.07 & 1.16 & 1.24 & 1.47 & 1.93 & 2.87 \\
\hline III & 0.97 & 1.07 & 1.09 & 1.87 & 2.27 & 2.68 & 1.00 & 1.09 & 1.11 & 1.13 & 1.73 & 2.13 \\
\hline IV & 0.86 & 0.97 & 1.03 & 1.51 & 2.40 & 2.84 & 0.89 & 1.00 & 1.06 & 1.27 & 2.00 & 2.27 \\
\hline
\end{tabular}

Selanjutnya dari data tabel 6, dapat dibuat grafik hubungan antara CBR $\gamma_{\mathrm{d}}$ dengan komposisi campuran pada energi 10x, 30x, dan 65x dalam keadaan unsoaked maupun soaked dapat dilihat pada Gambar 11 dan Gambar 12. 


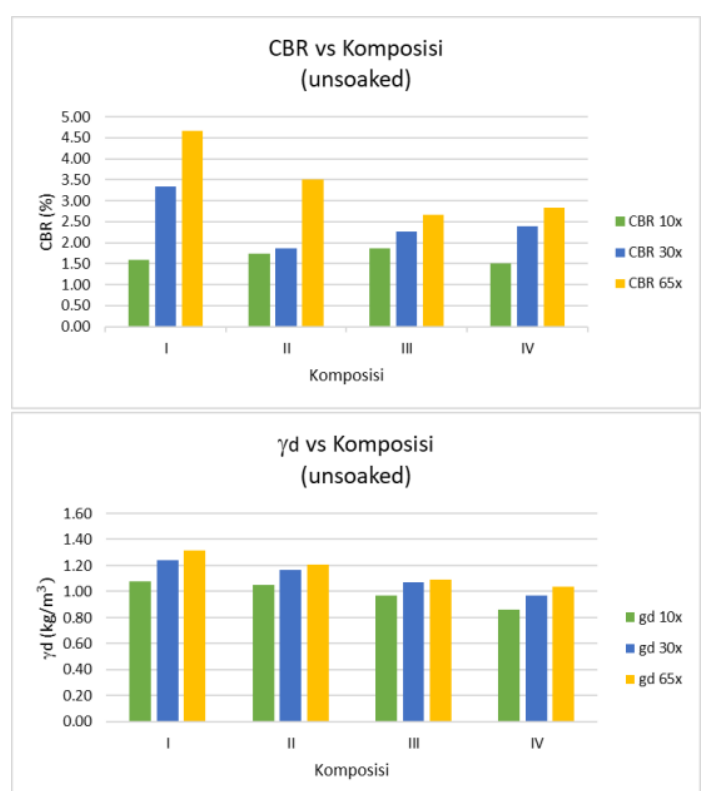

Gambar 11. Grafik CBR vs dan $\gamma_{\mathrm{d}}$ vs Komposisi (Unsoaked)

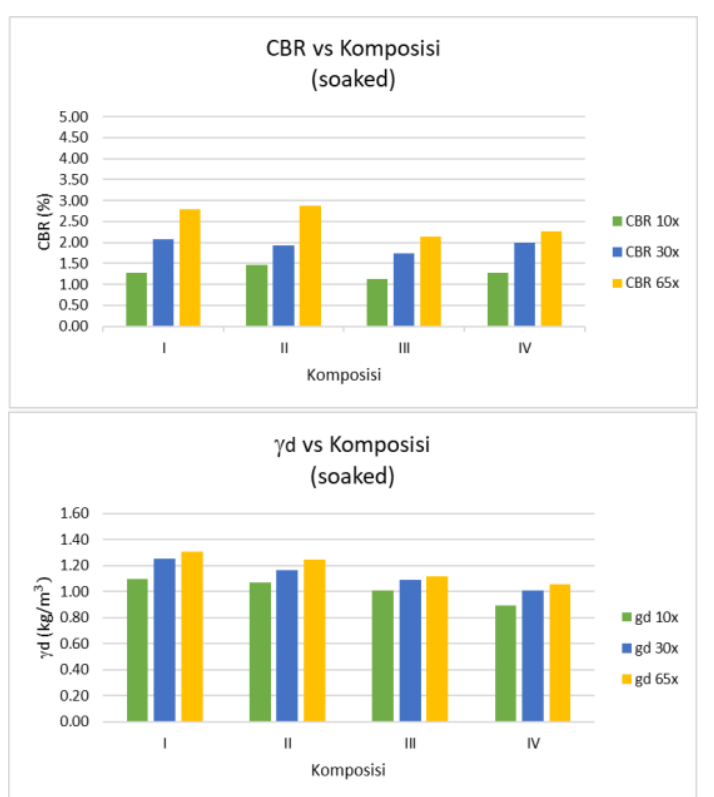

Gambar 12. Grafik CBR vs dan $\gamma_{\mathrm{d}}$ vs Komposisi (Soaked)

Pada kondisi soaked (Gambar 12), nilai CBR untuk semua komposisi campuran relatif sama, tetapi jika dibandingkan dengan kondisi unsoaked (Gambar 11), maka komposisi III dan IV yang relatif nilai CBRnya tidak menunjukkan penurunan yang besar.

\section{Masa peram 21 hari}

Hasil uji CBR dan nilai berat isi kering dengan masa peram 21 hari untuk setiap komposisi seperti terlihat pada Tabel 7.

Tabel 7. Hasil Pengujian CBR dengan Lama Masa peram 21 hari pada Keadaan Unsoaked dan Soaked

\begin{tabular}{|c|c|c|c|c|c|c|c|c|c|c|c|c|}
\hline \multicolumn{13}{|c|}{ Masa Peram 21 hari } \\
\hline & \multicolumn{6}{|c|}{ Unsoaked } & \multicolumn{6}{|c|}{ Soaked } \\
\hline & \multicolumn{3}{|c|}{$\gamma \mathbf{d}$} & \multicolumn{3}{|c|}{ CBR } & \multicolumn{3}{|c|}{$\gamma d$} & \multicolumn{3}{|c|}{ CBR } \\
\hline Komposisi & $10 x$ & 30x & $65 x$ & $10 x$ & $30 x$ & $65 x$ & $10 x$ & $30 x$ & $65 x$ & $10 x$ & 30x & $65 x$ \\
\hline I & 1.17 & 1.32 & 1.34 & 2.84 & 4.44 & 4.80 & 1.18 & 1.32 & 1.34 & 1.67 & 3.07 & 3.87 \\
\hline II & 1.07 & 1.18 & 1.26 & 2.40 & 3.47 & 3.93 & 1.06 & 1.17 & 1.23 & 1.16 & 2.22 & 3.07 \\
\hline III & 0.93 & 1.09 & 1.10 & 1.69 & 3.00 & 3.29 & 0.96 & 1.11 & 1.10 & 1.11 & 2.27 & 2.53 \\
\hline IV & 0.82 & 1.01 & 1.09 & 1.11 & 2.80 & 3.67 & 0.86 & 1.02 & 1.06 & 1.73 & 2.20 & 2.87 \\
\hline
\end{tabular}

Dari Tabel 7 dapat dibuat grafik hubungan antara CBR dan $\gamma_{\mathrm{d}}$ dengan komposisi campuran pada energi 10x, 30x, dan 65x dalam keadaan unsoaked maupun soaked dapat dilihat pada Gambar 13 dan Gambar 14. 


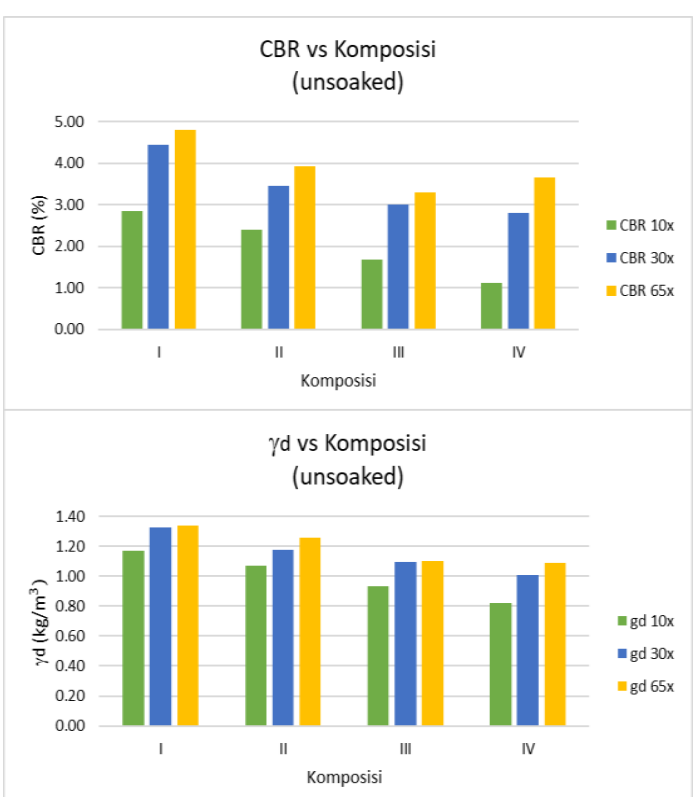

Gambar 13. Grafik CBR dan $\gamma_{\mathrm{d}}$ vs Komposisi (Unsoaked)

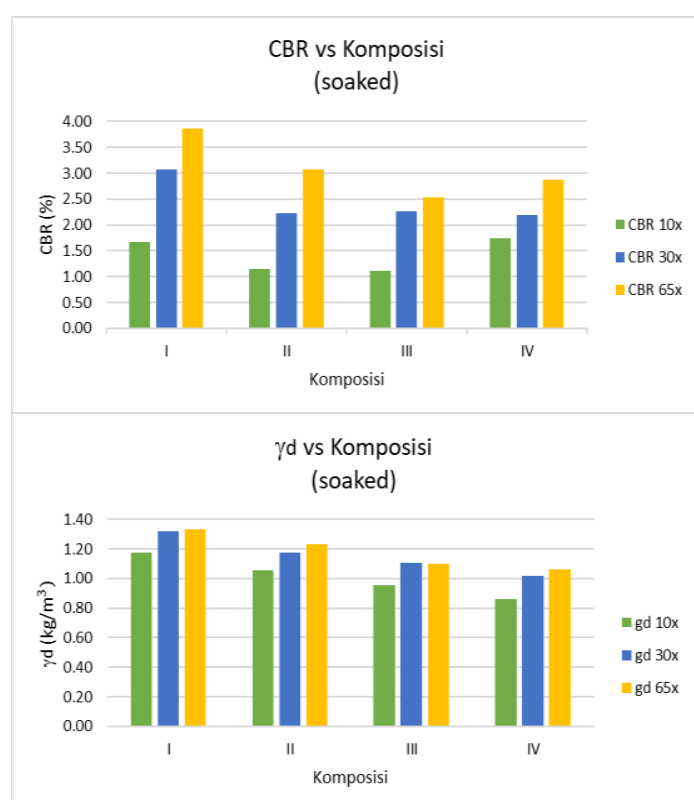

Gambar 14. Grafik CBR dan $\gamma_{\mathrm{d}}$ vs Komposisi (Soaked)

Pada kondisi soaked (Gambar 14), nilai CBR tertinggi di dapat pada komposisi I sedangkan komposisi yang lain lebih rendah. Nilai ini relatif sama dengan kondisi unsoaked (Gambar 13).

\subsection{Hasil CBR Campuran}

Selanjutnya jika digabungkan semua data pengujian, hasil uji CBR dan nilai berat isi kering kondisi unsoaked dan soaked dengan masa peram 3, 7, 14 dan 21 hari pada komposisi I, II, III, dan IV dengan tiga energi / tumbukan yang berbeda yaitu 10x, 30x, dan 65x, dapat dilihat pada tabel 8.

Tabel 8. Rekapan Pengujian CBR dalam Keadaan Unsoaked dan Soaked

\begin{tabular}{|c|c|c|c|c|c|c|c|c|c|c|c|c|c|}
\hline \multirow{3}{*}{$\begin{array}{l}\text { Curing } \\
\text { Time }\end{array}$} & \multirow{3}{*}{ Komposisi } & \multicolumn{6}{|c|}{ Unsoaked } & \multicolumn{6}{|c|}{ Soaked } \\
\hline & & \multicolumn{3}{|c|}{$\gamma \mathrm{d}$} & \multicolumn{3}{|c|}{ CBR } & \multicolumn{3}{|c|}{$\gamma \mathrm{d}$} & \multicolumn{3}{|c|}{ CBR } \\
\hline & & $10 x$ & $30 x$ & $65 x$ & $10 x$ & $30 x$ & $65 x$ & $10 x$ & $30 \mathrm{x}$ & $65 x$ & $10 x$ & $30 x$ & $65 x$ \\
\hline \multirow{4}{*}{3 hari } & I & 1.07 & 1.28 & 1.38 & 2.27 & 3.20 & 4.27 & 1.10 & 1.28 & 1.38 & 0.53 & 1.93 & 2.87 \\
\hline & II & 1.05 & 1.20 & 1.26 & 1.87 & 2.49 & 3.38 & 1.08 & 1.20 & 1.26 & 0.58 & 1.51 & 2.00 \\
\hline & III & 0.93 & 1.05 & 1.13 & 1.07 & 1.87 & 2.00 & 0.98 & 1.06 & 1.14 & 0.53 & 0.98 & 1.33 \\
\hline & IV & 0.91 & 1.01 & 1.06 & 1.02 & 1.33 & 1.51 & 0.94 & 1.00 & 1.05 & 0.22 & 0.67 & 0.93 \\
\hline \multirow{4}{*}{7 hari } & 1 & 1.09 & 1.25 & 1.34 & 0.89 & 3.91 & 4.80 & 1.12 & 1.28 & 1.35 & 0.49 & 1.60 & 2.13 \\
\hline & $\|$ & 1.07 & 1.18 & 1.26 & 2.40 & 3.47 & 3.93 & 1.06 & 1.17 & 1.23 & 1.16 & 2.22 & 3.07 \\
\hline & III & 1.02 & 1.29 & 1.57 & 2.93 & 2.84 & 3.38 & 1.03 & 1.06 & 1.60 & 0.44 & 1.33 & 2.20 \\
\hline & IV & 0.91 & 1.02 & 1.05 & 1.87 & 1.87 & 2.00 & 0.94 & 1.05 & 1.06 & 0.53 & 0.60 & 1.00 \\
\hline \multirow{4}{*}{$\begin{array}{c}14 \\
\text { hari }\end{array}$} & 1 & 1.08 & 1.24 & 1.32 & 1.60 & 3.33 & 4.67 & 1.10 & 1.25 & 1.31 & 1.27 & 2.07 & 2.80 \\
\hline & $\|$ & 1.05 & 1.16 & 1.21 & 1.73 & 1.87 & 3.51 & 1.07 & 1.16 & 1.24 & 1.47 & 1.93 & 2.87 \\
\hline & III & 0.97 & 1.07 & 1.09 & 1.87 & 2.27 & 2.68 & 1.00 & 1.09 & 1.11 & 1.13 & 1.73 & 2.13 \\
\hline & IV & 0.86 & 0.97 & 1.03 & 1.51 & 2.40 & 2.84 & 0.89 & 1.00 & 1.06 & 1.27 & 2.00 & 2.27 \\
\hline \multirow{4}{*}{$\begin{array}{c}21 \\
\text { hari }\end{array}$} & 1 & 1.17 & 1.32 & 1.34 & 2.84 & 4.44 & 4.80 & 1.18 & 1.32 & 1.34 & 1.67 & 3.07 & 3.87 \\
\hline & II & 1.07 & 1.18 & 1.26 & 2.40 & 3.47 & 3.93 & 1.06 & 1.17 & 1.23 & 1.16 & 2.22 & 3.07 \\
\hline & III & 0.93 & 1.09 & 1.10 & 1.69 & 3.00 & 3.29 & 0.96 & 1.11 & 1.10 & 1.11 & 2.27 & 2.53 \\
\hline & IV & 0.82 & 1.01 & 1.09 & 1.11 & 2.80 & 3.67 & 0.86 & 1.02 & 1.06 & 1.73 & 2.20 & 2.87 \\
\hline
\end{tabular}

\section{Penentuan Campuran Optimum}

Dari Tabel 8 terlihat nilai CBR yang berbeda untuk setiap pemberian energi yang berbeda dan juga nilai berat isi kering yang berbeda. Komposisi campuran optimum yang menghasilkan nilai CBR maksimum dan berat isi kering yang kecil pada keadaan unsoaked dan soaked adalah komposisi IV (83,25\% Tanah Asli + 16\% FA + 0,75\% EPS). Sedangkan masa peram diambil maksimal 14 hari, walaupun pada masa peram 21 hari menunjukkan nilai yang sedikit lebih baik dari masa peram 14 hari. Untuk masa peram lebih dari 14 hari bukan merupakan waktu yang efisien jika diterapkan di lapangan. Untuk perancangan tebal perkerasan nantinya digunakan nilai CBR pada kondisi soaked. Jika dibandingkan dengan nilai CBR yang sama pada kondisi tanah saja yaitu 1,0\% meningkat menjadi 2,3\% untuk pencampuran tanah dengan FA dan EPS (komposisi IV). 


\section{SIMPULAN DAN SARAN \\ 5.1 Simpulan}

Pencampuran tanah lempung dengan fly ash dan EPS, dapat meningkatkan nilai CBR dan menurunkan nilai berat isi kering tanah (timbunan). Nilai CBR kondisi soaked dari 1,0\% meningkat menjadi 2,27 \%, sedangkan nilai berat isi kering dari 1,23 gr/cm ${ }^{3}$ turun menjadi $1,06 \mathrm{gr} / \mathrm{cm}^{3}$. Komposisi campuran yang optimal adalah pada komposisi campuran IV dengan Tanah 83,25\% + FA $16 \%$ + EPS 0,75\% dengan masa peram selama 14 hari. Seperti halnya pada penelitian Apriyanti dkk., dan Inten Subowo penambahan fly ash meningkatkan nilai CBR yang signifikan, begitu juga pada penggunaan EPS hasil penelitian llluri dkk. dan Rocco dkk.

\subsection{Saran}

Optimasi penggunaan fly ash agar meningkat perlu ditambahkan bahan aktivasi lain, sehingga masa peram bisa dipersingkat dan memudahkan dalam pelaksanaan di lapangan. Selain dari peningkatan nilai CBR dan turunnya nilai berat isi kering, penelitian lain dapat dilakukan untuk mendapatkan parameter lainnya seperti nilai kuat tekan bebas $\left(\mathrm{q}_{\mathrm{u}}\right)$ dan potensi kembang susut (swelling) tanah.

\section{REFERENSI}

[1] Apriyanti, Yayuk dan Roby Hambali. 2014. "Pemanfaatan Fly Ash untuk Peningkatan Nilai CBR Tanah Dasar". Bangka Belitung : Universitas Bangka Belitung.

[2] Bina Marga. 2010. Spesifikasi Umum Bina Marga 2010 Divisi 3 : Pekerjaan Tanah.

[3] Das, Braja M. 1994. Mekanika Tanah Jilid 1. Jakarta : Erlangga.

[4] Illuri, Hema Kumar. 2007, "Development of Soil-EPS Mixes for Geotechnical Applications". School of Urban Development Centre for Build Environment and Engineering Research, Queensland University of Technology, Australia.

[5] Ingles dan Matcalf. Soil Stabilization: Principles and Practic.

[6] Injinering, civil. “ Pekerjaan Tanah”. http://civilinjinering.blogspot.co.id/2009/05/pekerjaan-tanah.html(26 Jan 2017) Nji, Lauw Tjun. Fly ash.

[7] Puslitbang Teknologi Mineral dan Batu bara. 2006. "Jurnal Teknologi Mineral dan Batu Bara No 37"

[8] Puslitbang, 2001. Panduan Geoteknik 1: Tanah Lunak Indonesia: Pembentukan dan Sifat-sifat Dasar.

[9] Puslitbang. 2002. Panduan Geoteknik 2: Tanah Lunak Indonesia: Penyelidikan Lapangan dan Pengujian Setempat pada Tanah Lunak.

[10] Rahmawati, Reni dan Andriani, Syifa, 2017, “Campuran Tanah Lempung dengan Menggunakan Expanded Polystyrene (EPS) dan Fly Ash (FA) sebagai Alternatif Timbunan Ringan pada Lapisan Subgrade", Politeknik Negeri Bandung.

[11] Rocco, Nicholas Thomas. 2012. "Characterization of Expanded Polystyrene (EPS) and Cohesive Soil Mixtures". Faculty of the Graduate School of Missouri University of Science and Technology.

[12] Subowo, Inten Setyowati Lestari. 2016. "Pengaruh Fly Ash Terhadap Nilai CBR Dan Sifat-sifat Propertis Tanah". Banten: Universitas Ageng Tirtayasa.

[13] Tim Geoteknik. 2009. Job Sheet Uji Tanah. Bandung : Politeknik Negeri Bandung.

[14] D. Amalia, Hendry, Kajian peningkatan nilai CBR tanah lempung Padalarang yang distabilisasi dengan vermikulit dan semen, Prosiding Seminar Nasional Aplikasi Teknologi Prasarana Wilayah, Surabaya, 2014, pp. D91-D95

[15] Kusuma Rama Indera, Mina Enden dan Utomo Akbar Prasetio, 2017, "Stabilisasi Tanah Menggunakan Fly Ash terhadap nilai Kuat Tekan Bebas berdasarkan variasi Kadar Air Optimum (Studi kasus Jalan Raya Bojonegara, Kab. Serang), Jurnal Teknik Sipil, Universitas Sultan Ageng Tirtayasa.

[16] Syahril, A.K. Somantri, A. Febriansya, The effect of EPS addition to soil stabilized with fly ash as lightweight fill materials for embankment construction, J. Phys: Conf. Ser 1364012077 (2019). DOI: 10.1088/1742-6596/1364/1/012077

[17] Andreas Dharmawan Huri, Kristian Yulianto, Sri Prabandiyani Retno Wardani, dan Siti Hardiyati, 2013, "Stabilisasi Tanah dengan Fly Ash dan Semen untuk Badan Jalan PLTU Asam-Asam”, Jurnal Teknik Sipil Universitas Diponegoro Semarang. 